\title{
Selective increase in plasma luteinising hormone concentrations in drug free young men with mania
}

\author{
L J WHALLEY, J E CHRISTIE, J BENNIE, H DICK, I M BLACKBURN, D BLACKWOOD, \\ G SANCHEZ WATTS, G FINK
}

\begin{abstract}
The hypothalamic-pituitary-gonadal system was investigated in drug free young men with either mania or acute schizophrenia and in age matched controls by measuring, at frequent intervals during a 17 hour "neuroendocrine day," plasma concentrations of luteinising hormone (LH), follicle stimulating hormone, prolactin, testosterone, sex hormone binding globulin (SHBG), and cortisol. Plasma LH in mania was significantly increased compared with the control value at all time periods and increased in the morning and evening samples compared with values in the schizophrenic patients. Plasma prolactin and cortisol concentrations were significantly greater in mania and schizophrenia compared with control values at several times during the day, but there were no significant between group differences in plasma testosterone or SHBG.

These results show that (a) in young men with mania there is a major disturbance in the central mechanisms that control the release of $\mathrm{LH},(\mathrm{b})$ the control of prolactin and cortisol secretion is abnormal in mania and acute schizophrenia, and (c) plasma LH concentrations may provide a useful hormonal diagnostic test for mania.
\end{abstract}

\footnotetext{
MRC Brain Metabolism Unit, Department of Pharmacology, Edinburgh, and Thomas Clouston Clinic, Edinburgh

L J WHALLEY, MD, MRCPSYCH, clinical scientist and consultant J E CHRISTIE, MPHIL, MRCPSYCH, clinical scientist and consultant

J BENNIE, MIBIOL, senior research officer

H DICK, MIST, technician

I M BLACKBURN, PHD, clinical scientist and clinical psychologist

D BLACKWOOD, PHD, MRCPSYCH, clinical scientist and senior registrar

G SANCHEZ WATTS, technician

G FINK, MD, DPHIL, director of MRC brain metabolism unit
}

Correspondence and requests for reprints to: Professor George Fink, MRC Brain Metabolism Unit, University Department of Pharmacology, Edinburgh EH8 9JZ.

\section{Introduction}

The clinical distinction between affective psychoses and schizophrenia forms the basis of modern systems of classification in psychiatry. Comparisons between these psychoses have shown important differences in symptoms and outcome, ${ }^{1}$ but no biological factor that distinguishes convincingly between schizophrenia and affective psychoses has been identified. We report a study of hypothalamic-pituitary-gonadal function in young men with either mania or schizophrenia and in healthy control subjects. Our aims were to identify hormonal factors that distinguished these psychoses from the normal state and to evaluate the potential contribution of the same hormonal factors to distinguish between schizophrenia and mania.

Dysfunction of the hypothalamic-pituitary-gonadal axis in chronic schizophrenia has been reported, ${ }^{2}$ but this axis has not been investigated systematically in a comparative study of acute schizophrenia and the affective psychoses. Diminished plasma concentrations of luteinising hormone (LH) and follicle stimulating hormone (FSH) have been found in chronic schizophrenia, ${ }^{2}$ and preliminary data suggest that plasma LH concentrations may be reduced in depression ${ }^{4}$ and increased in mania. ${ }^{5}$ These reports, together with observations that $(a)$ changes in sexual interest occur commonly in manic depressive illness, ${ }^{6}$ (b) schizophrenia and mania are rare before puberty, ${ }^{7}(c)$ the risk of mania is higher in women than men, ${ }^{6}(d)$ the age at onset of schizophrenia is appreciably lower in men than women, ${ }^{8}$ and $(e)$ the fertility of patients with schizophrenia is substantially reduced even before the onset of their illness, ${ }^{9}$ suggest that study of gonadotrophin secretion might contribute to the distinction between schizophrenia and mania. In addition to $\mathrm{LH}$ and FSH we also measured plasma concentrations of prolactin, testosterone, sex hormone binding globulin (SHBG), and cortisol in blood samples collected according to a sampling schedule which permits assessment of both circadian and pulsatile patterns of hormone release.

\section{Subjects and methods}

Male patients aged 16-49 years routinely admitted to the Royal Edinburgh Hospital were selected for study if they had symptoms of mania or schizophrenia and had not taken any neuroleptic or 
antidepressant drug for at least six months. Inclusion of any patient in the study required the consent of a close relative and the patient. The present state examination ${ }^{10}$ was completed within three weeks of admission, and information from this and a comprehensive clinical history were assessed independently six months after discharge by two psychiatrists (JEC and LJW). Diagnostic classification was made according to the research diagnostic criteria ${ }^{11}$ without knowledge of the results of endocrine investigations.

Twenty three patients were studied, 13 with schizophrenia, seven with mania, and three with schizoaffective disorder, manic subtype (mainly affective). One of the patients with mania had undergone orchiopexy at the age of 12 . Control subjects were recruited from the general population; none was taking any medication and each was matched to within 4 years of age of a manic patient. All controls and patients were in good physical health. When a patient's behaviour was a danger to himself or to others on the day of blood sampling 200 to $300 \mathrm{mg}$ amylobarbitone was given by mouth; six of the 13 schizophrenic and seven of the 10 manic patients were so treated but only on one or two occasions.

\section{BLOOD SAMPLING}

Blood samples $(10 \mathrm{ml})$ were withdrawn from an indwelling cannula (with a heparin lock) placed in a forearm vein about 20 minutes before the first sample at 0700 with subsequent samples withdrawn at $0730,0800,1500,1530,1600,2300,2330$, and 2400 . In six schizophrenic and five manic patients further samples were taken during and after recovery from illness. Blood was collected into lithium-heparin coated tubes containing 100 kallikrein inhibiting units of aprotinin (Trasylol) and kept at $4^{\circ} \mathrm{C}$ until centrifugation at $1600 \mathrm{~g}$ and $4^{\circ} \mathrm{C}$. The plasma was stored at $-40^{\circ} \mathrm{C}$.

\section{HORMONE ASSAYS}

Plasma concentrations of $\mathrm{LH}, \mathrm{FSH}$, and prolactin were determined by using National Institute of Arthritis, Diabetes, and Digestive and Kidney Diseases radioimmunoassay kits. The reference preparations were LH LER-907, FSH LER-907, and NIAMDD-hPRLRP-1 (AFP-2312C), respectively. Antirabbit $\gamma$ globulin (Scottish Antibody Production Unit, Carluke, Scotland) at a final dilution of $1 / 100$ was used as a second antibody. All samples were measured in duplicate. The sensitivities of the assays $\left(90^{\circ}\right.$ o sample counts bound/ total counts bound in the absence of unlabelled antigen (B/Bo)) were $0.6 \mathrm{IU} / 1$ for $\mathrm{LH}(100 \mu \mathrm{l}$ sample), $1.4 \mathrm{IU} / 1$ for FSH $(100 \mu \mathrm{l}$ sample), and $0.07 \mathrm{IU} / 1$ for prolactin (50 $\mu \mathrm{l}$ sample). The intraassay coefficients of variation were $4.6 \%$ (low pool, $1.32 \mathrm{IU} / 1$ ) and $3.2^{\circ}$ (high pool, $3.48 \mathrm{IU} / 1$ ) for $\mathrm{LH} ; 6.2^{\circ}$ (low pool, $2.72 \mathrm{IU} / \mathrm{l}$ ) and $2.9 \%$ (high pool, $8.94 \mathrm{IU} / 1$ ) for $\mathrm{FSH}$; and $7.0^{\circ}$ (low pool, $0.18 \mathrm{IU} / 1$ ) and $4.5^{\circ}$ (high pool, $1.38 \mathrm{IU} / \mathrm{l}$ ) for prolactin. The interassay coefficients of variation were $5.9 \%$ (low pool) and $5.0^{\circ}$ (high pool) for $\mathrm{LH}$, and $8 \cdot 4^{\circ}$ (low pool) and $8 \cdot 0^{\circ}$ (high pool) for prolactin. All the FSH concentrations were determined in a single assay.

Total testosterone concentrations were measured by radioimmunoassay using a modification of the method of Culbert ${ }^{12}$ and an antiserum (Miles-Yeda 61-315) raised in rabbits against testosterone-7-carboxymethyl-thioether-bovine serum albumin. The cross reaction of this antiserum was: testosterone $100 \%, 5 \alpha$-dihydrotestosterone $17 \%$, $5 \beta$-dihydrotestosterone $5 \%, 17 \alpha$-epitestosterone $0.8 \%$, androstenedione $6 \%$, 11-oxotestosterone $44^{\circ}$. Bound hormone was separated from free using dextran coated charcoal. The sensitivity of the assay for testosterone $(90 \% \mathrm{~B} / \mathrm{Bo})$ was $2.7 \mathrm{nmol} / 1(0.78 \mathrm{ng} / \mathrm{ml})$. The intra-assay coefficients of variation were $6.8^{\circ}$ o (low pool, $9.7 \mathrm{nmol} / 1$; $2.8 \mathrm{ng} / \mathrm{ml}$ ) and $8.2^{\circ}$ (high pool, $18.7 \mathrm{nmol} / \mathrm{l} ; 5.4 \mathrm{ng} / \mathrm{ml}$ ). The interassay coefficients of variation were $5.8 \%$ (low pool) and $6.5 \%$ (high pool).

SHBG concentrations were measured by a modification of the method of Anderson et al. ${ }^{13}$ The interassay and intra-assay coefficients of variation $(6 \cdot 1 \%$ and $5 \cdot 2 \%$ ) were assessed by measuring with each assay a pooled serum sample with a mean value of $13.7 \mathrm{nmol} / 1$ (in terms of specifically bound $5 \alpha$-dihydrotestosterone).

Total cortisol concentrations were determined by radioimmunoassay using a modification of the method of Seth and Brown ${ }^{14}$ and an antiserum (Scottish Antibody Production Unit) raised in sheep against cortisol-3-O-carboxymethyloxime-bovine serum albumin. The cross reaction of this antiserum as characterised by the Scottish Antibody Production Unit was : cortisol $100 \%$, corticosterone $0.18 \%$, cortisone $0.07 \%$, 21-deoxycortisone $0.30 \%, 11$-deoxycorticosterone $0.03 \%$, 11 -deoxycortisol $0.58 \%, \quad 17 \alpha$-hydroxyprogesterone $2.1 \%$, dexamethasone $0.33 \%$. Antisheep/goat serum (Scottish Antibody Production Unit) at a final tube dilution of $1 / 83$ was used as the second antibody. The sensitivity of the assay for cortisol $(90 \% \mathrm{~B} / \mathrm{Bo})$ was $11.6 \mathrm{nmol} / 1(0.42 \mu \mathrm{g} / 100 \mathrm{ml})$. The intra-assay coefficients of variation were $2.2 \%$ (low pool, $153 \mathrm{nmol} / 1 ; 5.54 \mu \mathrm{g} / 100 \mathrm{ml}$ ), $2.8 \%$ (middle pool, $311 \mathrm{nmol} / 1 ; 11.3 \mu \mathrm{g} / 100 \mathrm{ml}$ ), and $3.2 \%$ (high pool, $560 \mathrm{nmol} / 1 ; 20.3 \mu \mathrm{g} / 100 \mathrm{ml}$ ). The interassay coefficients of variation were $4 \cdot 6{ }^{\circ}$ (low pool), $2 \cdot 68 \%$ (middle pool), and $6.34 \%$ (high pool).

\section{STATISTICAL ANALYSIS}

Hormone concentrations for each sampling period (morning: 0700, 0730, 0800; afternoon: 1500, 1530, 1600; evening: 2300, 2330, 2400 ) were averaged and, because these data were not normally distributed, the Mann-Whitney $U$ test used to determine the significance of differences among the three groups. All 54 possible comparisons among the three groups were made, so that by chance alone up to four significant differences were expected (three at the $5 \%$ level and one at the $2 \%$ level). The manic patient with a history of orchiopexy (case 3, see table II) was excluded from all statistical analyses so that the three groups comprised (a) nine manic patients (includirg three with schizoaffective disorder, manic subtype), (b) 13 patients with schizophrenia, and (c) 13 normal controls.

\section{Results}

Comparisons of values in the morning, afternoon, and evening (tables I and II) showed that the plasma LH concentrations in the nine manic subjects were significantly greater than those in the patients with schizophrenia (morning: $p<0.02$; evening: $p<0.02$ ) and in the controls (morning: $p<0.02$; afternoon: $p<0.02$; evening: $\mathrm{p}<0.02$ ). Plasma prolactin concentrations were higher in both schizophrenia (morning: $\mathrm{p}<0.002$; afternoon: $\mathrm{p}<0.02$ ) and mania (morning: $\mathrm{p}<0.02$; afternoon: $\mathrm{p}<0.002$ ) than in the controls.

TABLE I-Plasma concentrations of luteinising hormone ( $L H)$, follicle stimulating hormone (FSH), prolactin, testosterone, sex hormone binding globulin (SHBG), and cortisol in young men with mania or schizophrenia and in normal controls. Each value is mean of three concentrations measured during morning, afternoon, and evening ( for times see text). (Standard deviations given in parentheses)

\begin{tabular}{|c|c|c|c|c|c|c|}
\hline & $\mathrm{LH}(\mathrm{IU} / 1)$ & $\mathrm{FSH}(\mathrm{IU} / 1)$ & Prolactin (IU/1) & Testosterone ( $\mathrm{nmol} / \mathrm{l})$ & SHBG $(\mathrm{nmol} / \mathrm{l})$ & Cortisol $(\mathrm{nmol} / \mathrm{l})$ \\
\hline \multicolumn{7}{|c|}{ Patients with mania $(n=9)$} \\
\hline $\begin{array}{l}\text { Morning } \\
\text { Afternoon } \\
\text { Evening }\end{array}$ & $\begin{array}{l}3.40(1.13)^{* *+} \\
3.16(1.33)^{* *} \\
3.43(1.24)^{* *+}\end{array}$ & $\begin{array}{l}4.22(0.62) \\
4.00(0.66) \\
3.90(0.74)\end{array}$ & $\begin{array}{l}1.19(1.05)^{* *} \\
0.83(1.02)^{* * *} \\
0.90(1.26)\end{array}$ & $\begin{array}{ll}22 \cdot 5 & (4 \cdot 2) \\
21 \cdot 5 & (7 \cdot 6) \\
18 \cdot 7 & (5 \cdot 5)\end{array}$ & $\begin{array}{l}22 \cdot 4(8.9) \\
29.9(13.7) \\
28.3(6.8)\end{array}$ & $\begin{array}{l}480(143) \\
295(166) * \\
204(174)\end{array}$ \\
\hline \multicolumn{7}{|c|}{ Patients with schizophrenia $(n=13)$} \\
\hline $\begin{array}{l}\text { Morning } \\
\text { Afternoon } \\
\text { Evening }\end{array}$ & $\begin{array}{l}2.54(0.82) \dagger \\
2.34(0.79) \\
2.33(0.79) \dagger\end{array}$ & $\begin{array}{l}5 \cdot 12(2 \cdot 40) \\
4 \cdot 88(2 \cdot 26) \\
4 \cdot 58(2 \cdot 12)\end{array}$ & $\begin{array}{l}0.59(0.22)^{* * *} \\
0.35(0.13)^{* *} \\
0.42(0.18)\end{array}$ & $\begin{array}{ll}20.8 & (6.9) \\
17.3 & (5.9) \\
15.9 & (5.9)\end{array}$ & $\begin{array}{ll}25 \cdot 7 & (7 \cdot 8) \\
20 \cdot 9 & (6 \cdot 2) \\
24 \cdot 1 & (9 \cdot 0)\end{array}$ & $\begin{array}{l}524(121) \\
326(110)^{* *} \\
251(163)\end{array}$ \\
\hline \multicolumn{7}{|c|}{ Controls $(n=13)$} \\
\hline $\begin{array}{l}\text { Morning } \\
\text { Afternoon } \\
\text { Evening }\end{array}$ & $\begin{array}{l}2.27(0.62) \\
2.08(0.56) \\
2.30(0.67)\end{array}$ & $\begin{array}{l}4.32(1.58) \\
4.22(1.70) \\
4.22(1.68)\end{array}$ & $\begin{array}{l}0.29(0.09) \\
0.21(0.04) \\
0.30(0.14)\end{array}$ & $\begin{array}{ll}18 \cdot 4 & (6 \cdot 2) \\
15 \cdot 3 & (6 \cdot 9) \\
15 \cdot 1 & (5 \cdot 2)\end{array}$ & $\begin{array}{ll}19 \cdot 7 & (4 \cdot 8) \\
21 \cdot 2 & (7 \cdot 1) \\
22 \cdot 0 & (6 \cdot 9)\end{array}$ & $\begin{array}{l}436(174) \\
207(74) \\
185(182)\end{array}$ \\
\hline
\end{tabular}

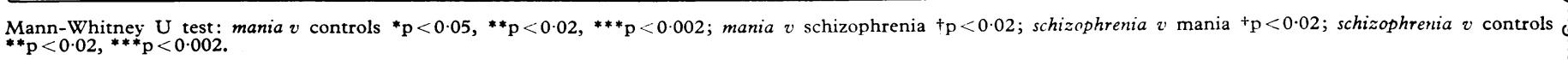


TABLE II-Plasma concentrations of luteinising hormone ( $L H)$, follicle stimulating hormone $(F S H)$, prolactin, testosterone, sex hormone binding globulin (SHBG), and cortisol in individual patients. Values are means of estimations in nine samples taken throughout "neuroendocrine day" in young men with either mania or schizophrenia and in normal controls

\begin{tabular}{|c|c|c|c|c|c|c|c|}
\hline $\begin{array}{l}\text { Case } \\
\text { control } \\
\text { No }\end{array}$ & Age (years) & $\mathrm{LH}(\mathrm{IU} / 1)$ & $\mathrm{FSH}(\mathrm{IU} / 1)$ & Prolactin (IU/1) & Testosterone $(\mathrm{nmol} / \mathrm{l})$ & SHBG $(\mathrm{nmol} / \mathrm{l})$ & Cortisol (nmol/1) \\
\hline \multicolumn{8}{|c|}{ Patients with mania } \\
\hline $\begin{array}{r}1 \\
2 \\
3 \\
4 \\
5 \\
6 \\
7 \\
8 \\
9 \\
10\end{array}$ & $\begin{array}{l}17 \\
22 \\
24^{*} \\
32 \\
34 \\
49 \\
33 \\
19^{+} \\
29^{+} \\
40^{+}\end{array}$ & $\begin{array}{l}3.19 \\
3.50 \\
7.27 \\
2.75 \\
2.91 \\
3.65 \\
3.37 \\
5.84 \\
1.69 \\
3.17\end{array}$ & $\begin{array}{r}3.56 \\
3.78 \\
16.70 \\
3.66 \\
3.76 \\
4.38 \\
3.90 \\
5.46 \\
2.98 \\
4.30\end{array}$ & $\begin{array}{l}0.69 \\
0.45 \\
0.76 \\
0.25 \\
0.47 \\
1.86 \\
3.59 \\
0.65 \\
0.56 \\
0.23\end{array}$ & $\begin{array}{l}20 \cdot 0 \\
20 \cdot 8 \\
20 \cdot 8 \\
34 \cdot 0 \\
20 \cdot 1 \\
18 \cdot 6 \\
19 \cdot 4 \\
20 \cdot 4 \\
13 \cdot 7 \\
19 \cdot 8\end{array}$ & $\begin{array}{l}27 \cdot 0 \\
31 \cdot 4 \\
46 \cdot 7 \\
42 \cdot 6 \\
22 \cdot 7 \\
29 \cdot 0 \\
21 \cdot 3 \\
22 \cdot 2 \\
17 \cdot 4 \\
28 \cdot 2\end{array}$ & $\begin{array}{l}366 \\
386 \\
469 \\
331 \\
331 \\
342 \\
138 \\
234 \\
469 \\
571\end{array}$ \\
\hline \multicolumn{8}{|c|}{ Patients with schizophrenia } \\
\hline $\begin{array}{l}11 \\
12 \\
13 \\
14 \\
15 \\
16 \\
17 \\
18 \\
19 \\
20 \\
21 \\
22 \\
23\end{array}$ & $\begin{array}{l}16 \\
21 \\
22 \\
32 \\
36 \\
36 \\
29 \\
18 \\
19 \\
25 \\
37 \\
21 \\
21\end{array}$ & $\begin{array}{l}2.12 \\
1.75 \\
2.19 \\
1.84 \\
2.90 \\
3.07 \\
2.17 \\
1.99 \\
4.08 \\
2.26 \\
1.95 \\
2.80 \\
2.30\end{array}$ & $\begin{array}{l}2.72 \\
\mathbf{4} \cdot 12 \\
2.56 \\
2.62 \\
\mathbf{4} \cdot 34 \\
9.04 \\
\mathbf{4} \cdot 14 \\
5.06 \\
7.48 \\
3.50 \\
2.96 \\
7.30 \\
7.70\end{array}$ & $\begin{array}{l}0.70 \\
0.37 \\
0.65 \\
0.37 \\
0.32 \\
0.63 \\
0.35 \\
0.60 \\
0.45 \\
0.48 \\
0.33 \\
0.35 \\
0.28\end{array}$ & $\begin{array}{l}32 \cdot 6 \\
12 \cdot 1 \\
18 \cdot 0 \\
16 \cdot 3 \\
11 \cdot 4 \\
11 \cdot 4 \\
21 \cdot 2 \\
14 \cdot 2 \\
25 \cdot 0 \\
20 \cdot 4 \\
20 \cdot 4 \\
16 \cdot 3 \\
13 \cdot 9\end{array}$ & $\begin{array}{l}24 \cdot 7 \\
16 \cdot 9 \\
23 \cdot 6 \\
18 \cdot 8 \\
35 \cdot 3 \\
17 \cdot 3 \\
31 \cdot 2 \\
27 \cdot 0 \\
29 \cdot 7 \\
23 \cdot 0 \\
21 \cdot 0 \\
20 \cdot 1 \\
17 \cdot 8\end{array}$ & $\begin{array}{l}295 \\
146 \\
306 \\
331 \\
530 \\
\\
226 \\
535 \\
359 \\
320 \\
254 \\
516 \\
281\end{array}$ \\
\hline \multicolumn{8}{|c|}{ Controls } \\
\hline $\begin{array}{l}24 \\
25 \\
26 \\
27 \\
28 \\
29 \\
30 \\
31 \\
32 \\
33 \\
34 \\
35 \\
36\end{array}$ & $\begin{array}{l}18 \\
24 \\
25 \\
34 \\
37 \\
48 \\
37 \\
20 \\
22 \\
37 \\
26 \\
29 \\
33\end{array}$ & $\begin{array}{l}2.55 \\
1.64 \\
1.99 \\
2.30 \\
2.15 \\
2.69 \\
2.44 \\
2.05 \\
2.98 \\
2.15 \\
2.72 \\
2.00 \\
1.20\end{array}$ & $\begin{array}{l}3.36 \\
3.88 \\
3.20 \\
4.26 \\
4.24 \\
5.98 \\
4 \cdot 14 \\
2.79 \\
8.84 \\
3.42 \\
4.54 \\
4 \cdot 28 \\
2.38\end{array}$ & $\begin{array}{l}0.30 \\
0.20 \\
0.26 \\
0.18 \\
0.24 \\
0.28 \\
0.34 \\
0.25 \\
0.21 \\
0.33 \\
0.48 \\
0.20 \\
0.52\end{array}$ & $\begin{array}{r}10 \cdot 1 \\
21.8 \\
20.5 \\
11.8 \\
11 \cdot 1 \\
21.8 \\
17.0 \\
18 \cdot 0 \\
15.9 \\
18.4 \\
13.9 \\
26 \cdot 0 \\
5.2\end{array}$ & $\begin{array}{l}27 \cdot 1 \\
15 \cdot 2 \\
19 \cdot 8 \\
17 \cdot 0 \\
32 \cdot 9 \\
19 \cdot 0 \\
22 \cdot 5 \\
23 \cdot 5 \\
17 \cdot 2 \\
25 \cdot 3 \\
24 \cdot 1 \\
12 \cdot 9 \\
16 \cdot 2\end{array}$ & $\begin{array}{l}157 \\
146 \\
464 \\
384 \\
201 \\
287 \\
155 \\
215 \\
281 \\
157 \\
408 \\
246 \\
331\end{array}$ \\
\hline
\end{tabular}

*Orchiopexy at age 12 (omitted from statistical analysis).

Schizoaffective disorder (manic subtype).

Conversion: SI to traditional units-Testosterone: $1 \mathrm{nmol} / 1 \approx 0.3 \mathrm{ng} / \mathrm{ml}$. SHBG: $1 \mathrm{nmol} / 1 \approx 0 \cdot 3 \mathrm{ng} / \mathrm{ml}$. Cortisol: $1 \mathrm{nmol} / 1 \approx 0 \cdot 04 \mu \mathrm{g} / 100 \mathrm{ml}$.

Plasma cortisol concentrations were greater in the afternoon in mania $(p<0.05)$ and schizophrenia $(p<0.02)$ than in the controls but there were no significant differences in the morning and evening values. There were no significant differences in average plasma concentrations of FSH, testosterone, or SHBG. The highest FSH concentrations (between 14.4 and $19 \cdot 4 \mathrm{IU} / 1$ were found in the manic patient (excluded from statistical analysis) with a history of orchiopexy.

Because there was no diurnal variation in the plasma $\mathrm{LH}$ concentration the average of all nine values was determined for each subject. The mean values in controls were all less than $3.0 \mathrm{IU} / 1$ $(50 \mathrm{ng} / \mathrm{ml}$; in terms of the bioassay potency of the standard LER 907) (figure). When this value was used as a threshold only two patients with schizophrenia had mean values above $3.0 \mathrm{IU} / 1$ and three patients with mania had mean concentrations below $3.0 \mathrm{IU} / 1$. No similar division between schizophrenic and manic patients could be made on the basis of mean values of any of the other hormones. The mean plasma LH concentrations after recovery in six schizophrenic patients (compared with values on admission) were 1.21 (1.84), $1.51(2.30), 2.23(1.95), 1.07(2 \cdot 12), 2.65(3.07)$, and 3.14 (4.08) IU/1, and in five manic patients 2.05 (2.75), $9.93(7.27), 4.43$ (3.50), $1 \cdot 70(3 \cdot 17)$, and $2.60(3.65) \mathrm{IU} / 1$.

When the hormone values in the schizophrenic and manic patients were combined there were no significant differences in the mean plasma concentrations of $\mathrm{LH}$ or prolactin between patients treated with amylobarbitone $(n=13$; mean $\mathrm{LH}$ concentration $3 \cdot 16$ (SD 1.47) $\mathrm{IU} / 1$, mean prolactin concentration $0.49(0 \cdot 18) \mathrm{IU} / \mathrm{l})$ and those not so treated $(n=10$; mean LH concentration 2.49 (SD 0.64 ) IU/l, mean prolactin concentration $0.82(1.05) \mathrm{IU} / 1)$.

\section{Discussion}

These results show, firstly, that in young men with mania plasma concentrations of LH are significantly greater than in young men with acute schizophrenia and in age and sex matched normal controls, and, secondly, that plasma concentrations of prolactin are significantly increased in young men with either mania or acute schizophrenia during the morning and afternoon.

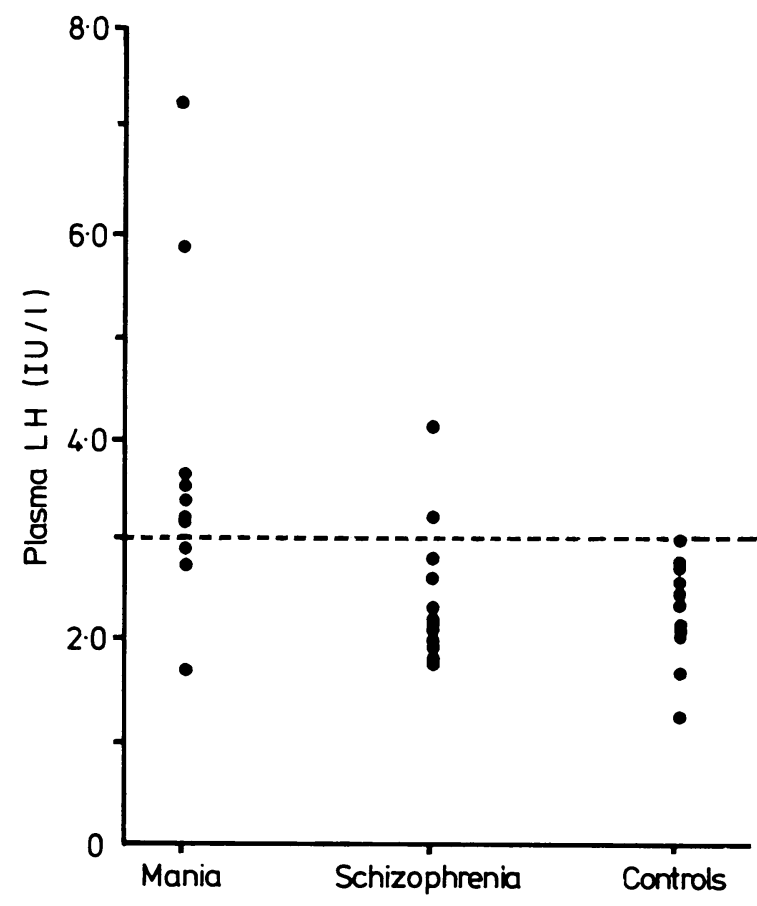

Mean plasma luteinising hormone ( $\mathrm{LH}$ ) concentrations based on nine estimations in "neuroendocrine day" studies carried out on young men with mania or schizophrenia or normal controls. (..... Threshold based on highest value in controls.)

High plasma prolactin and LH concentrations were not associated with treatment with amylobarbitone.

The secretion of $\mathrm{LH}$ in men is primarily regulated by a negative feedback of androgens, especially testosterone, sec- 
reted by the testes. Since plasma concentrations of testosterone in manic patients did not differ significantly from those in control subjects, the high plasma LH concentrations in mania cannot be attributed to a decrease in the negative feedback action of testosterone. The increase in LH secretion in mania also cannot be attributed to a decrease in the amount of free testosterone, since there were no significant differences in plasma concentrations of SHBG between the patients with mania and those with schizophrenia or the controls. Hence the increased secretion of $\mathrm{LH}$ in young men with mania is likely to be due to increased activity in the central systems that control LH release. Neural control of LH release is mediated by $\mathrm{LH}$ releasing hormone $(\mathrm{LHRH})$, the release of which is modulated by steroids and central monoaminergic and opioid neurones. ${ }^{15-18}$ Thus, for example, increased secretion of $\mathrm{LH}$ may be due to increased release of LHRH into hypophysial portal blood brought about by decreased central opioid activity, increased central noradrenergic activity, decreased central dopaminergic activity, or a combination of these factors and possibly others, such as decreased melatonin secretion. ${ }^{19}$ In addition to increased release of LHRH into the hypophysial portal circulation, the activity of LHRH neurones may also be increased in other systems, ${ }^{20-22}$ where LHRH might be a factor in the mediation of some behavioural aspects of mania such as increased sexual interest.

These data show an apparent dissociation between the secretion of FSH and LH. This is not surprising, since several studies have shown dissociation between the secretion of these two hormones in man as well as in animals. ${ }^{23}$ Although LHRH stimulates the release of FSH as well as $\mathrm{LH}$, once initiated the release of $\mathrm{FSH}$-in contrast to $\mathrm{LH}$-does not require the minute to minute control by LHRH. Steroids exert different effects on the spontaneous release of the two gonadotrophins and, in males in particular, FSH secretion is also significantly affected by the putative testicular hormone inhibin. A reduction in inhibin secretion may explain the high plasma FSH concentrations in the patient who required orchiopexy at the age of 12, whose plasma FSH concentrations were more than four times the mean concentration in manic patients $(4.04 \mathrm{IU} / 1)$. The relatively high concentration of $\mathrm{LH}$ in this patient may have been due to a reduction in the negative feedback effect of testosterone. This assertion is based on the fact that the patient's plasma concentrations of total testosterone were in the normal range but his plasma concentration of SHBG was higher than the values in all the other patients and controls (table II). Abnormal gonadal function may be related to the susceptibility to manic depressive illness, an interpretation supported by the persistence of increased plasma $\mathrm{LH}$ concentrations in two out of five patients who had recovered from the manic phase of their illness. Degenerative changes have been reported in testicular biopsy samples from patients with chronic schizophrenia, ${ }^{24}$ and, although there have been changes in diagnostic criteria, these data ${ }^{24}$ suggest that testicular function may be impaired in subtypes of psychosis.

The mechanism of the increased secretion of prolactin in both the manic and schizophrenic patients is as difficult to interpret as the changes in gonadotrophin secretion. The secretion of prolactin may be inhibited by dopaminergic activity, $r$-aminobutyric acid, and somatostatin and stimulated by several peptides such as thyrotrophin releasing hormone, the enkephalins, $\beta$-endorphin, and vasoactive intestinal peptide (see review ${ }^{25}$ ). Thus our results might be interpreted to mean that in acute schizophrenia and mania central dopaminergic activity is significantly decreased. This would appear to conflict with the hypothesis that in schizophrenia there is an increase in central dopaminergic activity which, theoretically, should lead to a decrease in the secretion of prolactin. It might also be argued, however, that the activity of the tuberoinfundibular neurones, which release dopamine into the hypophysial portal vessels, does not reflect the activity of other central dopaminergic neurones. Alternatively, increased central dopaminergic activity may indeed be present in the psychoses, but in our patients this was masked by a greater increase in activity of one or more putative prolactin releasing factors. ${ }^{25}$ Clearly, in order to understand the changes of prolactin as well as LH and FSH, more basic information is required on the neurotransmitter interactions concerned in the control of these pituitary hormones.

We thank Mrs P Ritchie and Mr J Sloan-Murphy for their expert care of the patients and research work, Miss Jo Donnelly for preparing the manuscript, and the National Hormone and Pituitary Program of the National Institute of Arthritis, Diabetes, and Digestive and Kidney Diseases, Baltimore, Maryland, for the generous provision of radioimmunoassay materials.

\section{References}

1 Brockington IF, Kendell RE, Wainwright S, Hillier VF, Walker J. The distinction between affective psychoses and schizophrenia. Br 7 Psychiatry 1979;135

IN, Cotes PM, Crow TJ, Johnstone EC. Gonadot

3 Altman N, Sachar EJ, Gruen PH Red 1982;12:263-73. menopausal depressed women. Psychosom Med 1975;37:274-6.

4 Rubin RT, Poland RE, Tower BB, Hart PA, Blodgett ALN, Forster B. Hypothalamo-pituitary-gonadal function in primary endogenously depressed men: preliminary findings. In: Fuxe K, Gustafsson JA, Watterberg L, eds. Steroid regulation of the brain. Oxford: Pergamon Press, 1981:387-96.

Benkert $O$. Studies on pituitary hormones and releasing hormones in depression and sexual impotence. Prog Brain Res 1975;42:25-36.

作 ère, Tindall, and Cassell,

Loranger AW. Sex

(rom schizophrenia or affective disorders. Maudsley Monograph 1969 ; No 19.

10 Wing J, Cooper JE, Sartorius. N. Measurement and classification of psychiatric symptoms. An instruction manual for the PSE and CATEGO programme. Cambridge. University Press, 197

1 Spitzer RL, Endicott J, Robins E. Research diagnostic criteria $(R D C)$ for a selected group of functional disorders. New York: New York State Department of 1975

12 Culbert J. Improved extraction of steroid hormones from the blood plasma of the domestic fowl (Gallus domesticus) using light petroleum at elevated temperatures. Analyst 1976;101:391-5.

13 Anderson DC, Lasley BL, Fisher RA Shepherd JH, Newman L, Hendrickx AG Transplacental gradients of sex-hormone-binding-globulin in human and

14 Seth J, Brown LM. A simple radioimmunoassay for plasma cortisol. Clin Chim Acta 1978;86:109-20.

Fink G. Neuroendocrine control of gonadotrophin secretion. $\mathrm{Br}$ Med Bull Barraclough CA. Wise PM. The role of catecholamines in the regulation of pituitary luteinizing hormone and follicle-stimulating hormone secretion. pituitary luteinizing horm

17 Fink G, Stanley HF, Watts AG. Central nervous control of sex and gonadotropin release: peptide and nonpeptide transmitter interactions. In: Krieger D Brownstein M, Martin J, eds. Brain peptides. New York: John Wiley and Sons, Inc, 1983:413-35

8 Kalra SP, Kalra PS. Neural regulation of luteinizing hormone secretion in the rat. Endocr Rev 1983;4:311-51.

19 Waldhauser F, Weiszenbacher G, Frisch $H$, Zeitlhuber $U$, Waldhauser $M$ Wurtman RJ. Fall in nocturn

Sabum Y Pfaft DW. LH-RH in the mesencephalic central grey can potentiate the lordosis reflex of female rats. Nature 1980;283:566-7.

21 Shivers BD, Harlan RE, Morrell JT, Pfaff DW. Immunocytochemical localization of luteinizing hormone-releasing hormone in male and female rat brains. Quantitative studies on the effect of gonadal steroids. Neuroendocrinology $1983 ; 36: 1-12$.

22 Sirinathsinghii DJS, Whittington PE, Andsley A, Fraser HM. $\beta$ Endorphin regulates lordosis in female rats by modulating LH-RH release. Nature $1983 ; 301: 62-4$

23 Fink G. Feedback actions of target hormones on hypothalamus and pituitary with special reference to gonadal steroids. Annu Rev Physiol 1979;41:571-85. Hemphill RE, Reiss M, Taylor AL. Study of histology of testis in schizophrenia and other mental disorders. Fournal of Mental Science $1944 ; 90: 681-95$.
Leong PA, Frawley LS, Neill JD. Neuroendocrine control of prolactin secretion. Annu Rev Physiol 1983;45:109-27.

(Accepted 1 November 1984)

\section{ONE HUNDRED YEARS AGO}

A woman named Ann Little, 54 years of age, was charged on Tuesday last at the Gateshead county police-court with stealing one game-cock and two cats, and was sentenced to three months' imprisonment. In the course of the evidence it was stated that for some time past the prisoner has been in the habit of stealing cats, skinning them, and selling them to her neighbours as Scotch hares. About a fortnight ago, information to this effect was given to the police; and on the prisoner's house being searched, the remains of several cats were found. In and about the house were discovered no less than forty cats' skins, some of which have been identified by neighbours as the remains of their favourites. When charged with the offence, the prisoner replied, "I have sold several, and we have eaten several ourselves; they are very like a rabbit when cooked." (British Medical fournal 1885;i:393.) 